DOI: http://dx.doi.org/10.4314/ljh.v25i1.4

\title{
Swales' Cars Model and the Metaphor of Research Space: An illustration with an African Journal ${ }^{1}$
}

\author{
Gordon S. K. Adika \\ Senior Research Fellow, Language Centre, \\ University of Ghana, Legon
}

\begin{abstract}
John Swales' Create a Research Space (CARS) model comprising three rhetorical moves; namely, Move 1 (establish a research territory), Move 2 (establish a niche), and Move 3 (occupy the niche) describes the rhetorical strategies that researchers utilize in order to claim research space in their disciplines in a highly competitive research environment. This paper analyzes Moves 1 and 2 of the introductions in Research Articles (RAs) in an African journal in order to examine the space that the contributors to the journal allot to themselves through the linguistic devices used in signalling gap statements, along with the extensiveness of references to previous work as a way of situating and mainstreaming their research. To this end, the introductions of 59 RAs published in the Legon Journal of the Humanities from 2005 to 2010 were analyzed using the CARS model. The findings reveal that the authors of these RAs may perhaps not be exploiting Step 3 (reviewing items of previous research) under Move 1 in order to reinforce the research niche being claimed in Move 2.
\end{abstract}

Keywords: Genre analysis, introductions, Moves, scholarly communication, African journals

\footnotetext{
${ }^{1}$ The initial analysis of data and write-up of this paper were made possible by a Write-shop Project retreat organized by the University of Ghana under the auspices of UG-Carnegie "Next Generation of Academics in Africa Project"in 2012. I would also like to acknowledge the following academics for reading through drafts of the paper and offering valuable suggestions: Prof. KwesiYankah, former Pro-Vice Chancellor, University of Ghana (UG); Prof. Augustine H. Asaah, Department of French (UG); and Dr. Charles Asante, Language Centre (UG).
} 
As a descriptive and analytical tool, Swales' Create a Research Space (CARS) model (Swales 1981, 1984, 1990) has gained wide scholarly attention for the past two and half decades (See for example, Crookes 1986; Nwogu 1997; Anthony 1999; Posteguillo 1999; Bunton 2002; Samraj 2002). The CARS model, represented in the next section, proposes a move structure for research article introductions. Substantial research has been done in this area, and evidently, studies have been extended to diverse communicative events - from research article introductions to introductions in theses and dissertations, and then to abstracts. Research has also focused on cross-cultural and cross disciplinary variations. However, corpora for much of this research derive from western journals which in terms of the metaphor of space arguably dominate international scholarship. This paper attempts, therefore, to extend the discussion on the usefulness of the CARS model by applying it to some data collected from a journal published in Africa. It analyzes Moves 1 and 2 of the introductions in order to examine the research space that the contributors to this journal "rhetorically" allot to themselves through the linguistic devices used in signalling gap statements, along with the extensiveness of references to previous work as a way of situating and mainstreaming their research. Research space is defined in terms of the rhetorical configuration embodied in the CARS model; that is, the expanse or breadth of research territory negotiated, declared, or asserted through Move 2 and predicated on a depth of relevant items of previous research in Move 1.

\section{The CARS Model}

The CARS model relates the research enterprise to the struggle of a species to carve out an ecological space for itself in a competitive environment, and presents researchers as struggling for recognition and acceptance in a highly competitive research environment (Swales, 1990). In other words, scholars attempt to establish a research territory by making rhetorical moves (claiming centrality and/or making topic generalizations, along with a review of prior literature) that indicate that the topic of research is pertinent and constitutes part of a well-established research area. Thereafter, the scholar may create a research niche by specifying a gap - an inadequacy or a weakness in previous research. This then provides the basis or the motivation for a declaration of the intended research.

\section{The CARS (Create a Research Space) model for writing academic introductions Move 1: Establishing a territory}

Step 1 Claiming centrality and/or

Step 2 Making topic generalizations and/or

Step 3 Reviewing items of previous research 


\section{Move 2: Establishing a niche}

\section{Move 3: Occupying the niche}

Step 1a Counter-claiming or

Step 1b Indicating a gap or

Step 1c Question-raising or

Step 1d Continuing a tradition

Step 1a Outlining purposes or

Step 1b Announcing present research

Step 2 Announcing principal findings

Step 3 Indicating Research article structure

As Dudley-Evans (2000) puts it, the "model captures the way in which academic writers justify and highlight their own contribution to the ongoing research profile of the field by first establishing a topic for the research and summarizing the key features of the previous research, then establishing a gap or possible extension of that work that will form the basis of the writer's claims" (p. 5). Over the years, research related to the CARS model has largely focused on cross-cultural and cross-disciplinary variations in terms of the nature and range of the rhetorical moves. The influence of the model on genre analysis in terms of the range of applications is tremendous: a move-based approach has been used in the analysis of a variety of texts such as research articles, abstracts, and dissertations/theses (Dudley-Evans, 2000). Notable recent studies include Shehzad (2008) who focuses on Move 2 and presents an in-depth analysis of various types of gap statements used in Computer Science research article introductions; Al-Ali and Sahawneh's (2011) comparison of English and Arabic PhD dissertation abstracts in the field of linguistics in a cross-cultural study; and Kwan et al (2012) who analyze the micro area of evaluations in the literature reviews of research articles in the field of Information Systems. These studies underscore the usefulness of the generalized CARS model as a starting point for investigating the discourse structuring of genres.

\section{Move 2, Knowledge Construction, and the Metaphor of Space}

The relative importance of Move 2 derives from its role as an indicator of the relevance of the new or fresh research that the author is embarking upon. As a minicritique, most Move $2 \mathrm{~s}$ establish a niche by showing that the research story so far is not yet complete and highlight the motivation for the study. In terms of structure, Move $2 \mathrm{~s}$ are quite short, often consisting of no more than a sentence. The predominant linguistic devices used for signalling Move 2 (Shehzad, 2008) are: (i) Contrastive Statements (however, while, but, although, nevertheless, as opposed to, rather than); (ii) Quantifiers and quasi-negatives (limited, few, little, none of, no [work/research/data/study]); (iii) "Negative" verbs combined with contrastive statements (disregarded, ignored, been 
limited to, overlooked); and (iv) "Negative" adjectives (incomplete, inconclusive, misguided, unconvincing, unsatisfactory, flawed, and many other adjectives). Generally, the linguistic devices used in signalling Move $2 \mathrm{~s}$ are composite in nature or character, reflecting the complexity of making that discourse act. The significant issues here are how the linguistic choices made impact on strength of claim; and how the literature review (as presented in Move 1, Step 3) in turn affects the persuasive power of the strength of claim. These issues are important in view of the nature of knowledge construction in the humanities.

It would largely be presumptuous to attempt to delineate what constitutes knowledge construction in the humanities considering the broadness of the concept and the ideological tensions connected with cross-disciplinary and cross-cultural epistemological biases. Nonetheless, for the purposes of this study which locates itself in the general area of genre analysis and, specifically, focuses on the social interactive dimension of disciplinary discourses (as expounded in Hyland, 2004), explaining the nature of knowledge creation and dissemination in the humanities, albeit brief, is essential. In the humanities, new knowledge emerges through an accretive process in which authors explore the diversity of prior knowledge, mapping out the thematic landscape in terms of history and schools of thought, and dealing with the vast literature which typically invites interpretative challenges depending upon one's ideological viewpoint. As Hyland (2004) concludes:

Writers therefore often have to pay greater attention to elaborating a context through citation, reconstructing the literature in order to provide a discursive framework for their arguments and demonstrate a plausible basis for their claims. The more frequent citations in the soft texts therefore suggest greater care in firmly situating research within disciplinary frameworks and supporting claims with intertextual warrants (p. 31).

Hyland's comments show that in the humanities, locating research properly or firmly through a comprehensive review of prior knowledge is an imperative of the knowledge creation and dissemination process. Against this background, it is arguable that if introductions to research articles in the humanities are to effectively establish common ground as well as show persuasive force (that is, enable their authors to gain acceptability and recognition), then they must deploy the relevant rhetorical moves.

A major assumption that has directed the issues raised in this paper is, following Swales and Feak (2004), the notion that journals constitute authoritative and fast channels for scholars to communicate their research contributions to the wider scholarly community, and besides claim validation and recognition. They have thus become 
mainstream terrains for determining who and what gets published, with the major international journals, especially those published by Western outlets exercising more power and influence. This is hardly surprising since journal publication in Africa, in relation to Western journals which began more than three centuries ago, is a recent phenomenon, beginning from the early twentieth century with the 1950s witnessing quite a remarkable increase in the number of journals published across the continent (see Aina 1997; Myers 1999; Stilwell 2000). African journals constitute part of worldwide scholarly communication; implying therefore, that they provide outlets for members of the African academic discourse community to interact with the wider international scholarly community in order to gain recognition.

\section{Research Questions}

The specific research questions are as follows:

i. What steps characterize Move 2, and in this regard what expressions are used to indicate the steps?

ii. Is Move 2 predicated on a small, moderate, or extensive review of literature in Move 1 ?

iii. What do questions 1 and 2 reveal about the research space that the African scholar has been claiming?

\section{Method}

\section{The Corpus}

The corpus for this study was extracted from the Legon Journal of the Humanities which until 2013 was published by the Faculty of Arts, University of Ghana ${ }^{2}$. It is available on most electronic databases as well as public and national libraries globally. The corpus comprises the introductions to 59 articles published in the journal from 2005 to 2010 , constituting six editions of the journal. The word length of the entire corpus was 32,203 words. Each introduction was numbered and classified according to the year of publication; therefore, RP 27: (2007) Linguistics means "Research Paper Number 27 in the field of Linguistics and published in the 2007 edition of the Legon Journal of the Humanities". All the articles in each edition, with the exception of a keynote address, in Volume 10, 2010 comprised the data. The distribution was as follows: Language and Linguistics (19 RAs); Literature (20 RAs); History (2 RAs); Education (4 RAs); Performing Arts (7 RAs); Philosophy (4 RAs); Religions (3 RAs). This distribution indicates that the articles were predominantly from the inter-related disciplines of language, literature and linguistics, signalling therefore that the generalizations made in

\footnotetext{
${ }^{2}$ It is now published by the College of Humanities, University of Ghana, Legon.
} 
this paper may perhaps be more applicable to these disciplines than to, for instance, history, education, and the performing arts.

\section{The Procedure}

The introductions were analyzed using the CARS model as the analytical tool. Each introduction was numbered and classified according to the year of publication. All the introductions were read and assigned Moves and the sub-steps associated with the Moves. These were tabulated and percentages computed. For Move 2, the linguistic devices used to signal the gap statements were identified and compiled. The manual procedure adopted here derives its validation from Hyland (2004) who explains that computer-based "concordance techniques are unhelpful when dealing with move structure analyses ... because the schematic structure that writers employ to shape their purposes for a particular readership are [sic] not always explicitly marked linguistically, but more often draw on pragmatic understandings" (p. 140).

\section{Results}

Research Question 1: What steps characterize Move 2, and in this regard what expressions are used to indicate the steps?: Thirty-eight of the RAs, representing $65 \%$ of the samples, had clear Move $2 \mathrm{~s}$, and the distribution of the various steps (as captured in Table 1) was as follows: question raising (6 introductions representing 10.3\%) occurred predominantly in the field of Literature (that is, 5 out of the 6 cases); continuing with a tradition (5 introductions representing 8.5\%) was also predominantly in the area of literature; counter-claiming (1 introduction representing 1.7\%) occurred in philosophy; indicating a gap (26 introductions representing 44.5\%) occurred across disciplines. Thus, the following rhetorical devices were deployed: counter-claiming; indicating a gap; question-raising; and continuing a tradition. Linguistic devices used included contrastive statements, negative expressions, quantifiers, negative verbs combined with contrastive statements, and negative adjectives. On the flip side, 17 of the introductions $(28.8 \%$ of the sample size) did not have Move 2s, and this applied across the disciplines; while 4 (6.7\%) had implicit gap statements which refer to situations where Move $2 \mathrm{~s}$ had to be deduced from the extensive narrative or exposition. 


\section{Table 1}

Distribution of Steps in Move 2

Yes (38 RAs Representing 65\%)

\begin{tabular}{|l|l|}
\hline Move 2 & Percentage \\
\hline $\begin{array}{l}\text { Step 1a: } \\
\text { Counter-claiming }\end{array}$ & $1.7 \%$ \\
\hline $\begin{array}{l}\text { Step 1b: } \\
\text { Indicating a gap }\end{array}$ & $44.5 \%$ \\
\hline $\begin{array}{l}\text { Step 1c: } \\
\text { Question-raising }\end{array}$ & $10.3 \%$ \\
\hline $\begin{array}{l}\text { Step 1d: } \\
\text { Continuing a tradition }\end{array}$ & $8.5 \%$ \\
\hline
\end{tabular}

Research Question 2: Is Move 2 predicated on a small, moderate or extensive review of literature in Move 1?: In terms of the structural configuration in the Move analytical model, Step 3 under Move 1 may be further sub-categorized as Small (little or no reference to prior knowledge); Moderate (reasonable reference to prior knowledge); and Extensive (wide-ranging reference to prior knowledge); where "small", "moderate", and "extensive" index the expansiveness of prior knowledge that the author engages in order to locate his or her study or to justify the research niche. From this reference point, the degree of the review of previous literature or prior knowledge in the data is captured in Table 2 which shows that $61 \%$ of the RAs reviewed up to four items of preceding literature (small); while 27\% considered between 5 and 9 items (moderate); while 12\% made use of over 10 items (extensive):

\section{Table 2}

Extensiveness of Literature Reviews

\begin{tabular}{|l|l|}
\hline Items reviewed & Percentage \\
\hline$(0-4)$ & $61 \%$ \\
\hline$(5-9)$ & $27 \%$ \\
\hline$(10+)$ & $12 \%$ \\
\hline
\end{tabular}




\section{Discussion}

The inter-relationships between Moves 1 and 2 in terms of how they impact strength of claim (as expressed in research question 3 ) are discussed below.

\section{Strength of Claim: Move 2}

Strength of claim refers to the persuasive force conveyed by the introduction to the RA, and in this section it is discussed as a function of Move 2. Inevitably, a Move 2 in isolation cannot fulfil the adequacy conditions required for properly situating the new contribution within the discipline's epistemological framework. The various steps under Move 1 help to show why the article is important or worth publishing, and this is an important aspect of establishing a research territory; however, as regards establishing a niche, making an explicit Move 2 is a key rhetorical strategy. It must be pointed out that this does not necessarily transfer all the power to Move 2; the steps under Move 1 do play a necessary orientational function and help to create some contextualization for the new contribution to knowledge and why it should be published. The argument, however, is that where Move 2 is explicitly indicated, the establishment of the niche is much more strongly conveyed; where it is not, the reader carries the burden of spotting the relevance of the author's proposed contribution. This arguably weakens the strength of claim.

As noted above, remarkably, 17 (28.8\%) of the RAs had no Move 2s employing mostly the rhetorical pattern Move 1 to Move 3. In the following introduction, RP18: (2006) Linguistics, the absence of Move 2 numbs the author's attempt at announcing the new research:

RP18: (2006) Linguistics: Reduplication is the morphological process in which all or part of a word is copied. It is a process which is found in many languages across the world. Reduplication is used to achieve various kinds of functions, both lexical and grammatical. In Igbo, reduplication is employed to achieve different kinds of intensification such as action, taste, smell, colour, unspecified plurality and distributive uses (Anagbogu, 1995). McCarthy \& Prince $(1986,1990)$ studied reduplication in several languages including Ilokano, Arabic, and proposed ways of analyzing the process. Other studies of reduplication include Marantz (1982), McCarthy (1981). [No explicit Move 2; Establishment of niche rhetorically desirable] This paper examines reduplication in Ewe. The various reduplicative processes are explored. It is shown that Ewe reduplication performs either lexical or grammatical function. 
Apart from the presence or otherwise of a Move 2 influencing the strength of claim, the language used in making the move could also affect it. Strength of claim may also be characterized as robust or tentative. For example, in RP 28: (2007) Philosophy, the author proclaims: "Now, I don't buy this, and I'll explain why." Here the author makes a strong claim despite the dearth of items of previous literature as evident in the text below:

RP28: (2007) Philosophy: Talking about certain experiences being exclusively female and significant for that very reason is common among people analyzing gender. In order to look critically at the notion of a uniquely women's point of view, I'll discuss these two related statements:

Key aspects of human experience are polarized into two diametrically opposed, mutually exclusive ways of experiencing and being in the world, contoured by a combination of biology and social conditioning.

Women have special access to knowledge of aspects or reality through certain ways of sentient understanding that are inaccessible to men, that is women are capable of exercising a special intuition or sensitivity that lies outside the scope of male recognition or comprehension.

Now, I don't buy this, and I'll explain why. I hope to show that there is no good reason to assume that experiences acquired uniquely by women must be incomprehensible to men in some fundamental and insuperable way - nor vice versa. ...

In the case of RP34: (2008) Literature, the author's claim is highly tentative, probably on account of the small number (in this case three) of review of previous items of research: "If he did this for a study of Idanre and other poems and A Shuttle in the Crypt, [then] it is possible to do a study of this latest volume along the same route ..."

RP 34 (2008) Literature: Sarmakand and Other Markets I have known (2002) is the latest volume of poems by Wole Soyinka. It differs in tone and style from the earlier collections of poems such as Idanre and Other Poems (1967), A Shuttle in the Crypt (1972), OgunAbibiman (1976) and Mandella's Earth (1988). The difference is that while the earlier ones are based on intense metaphysical and sometimes mystical or psychological experience of the poet, this latest collection could be described as poems of the moment and therefore transitory because of the situations that induced their writing. ... Soyinka's poetry has earlier been criticised of wilful obscurity, of private esoterism and concerted opacity (Chinweizu et al 1975:11). His response to the charge of constructing syntax and imagery that are imprecise and opaque is that he draws his creative inspiration and aesthetic matrix from a broad cultural spectrum in a global level - which has allowed him to be selective in diction and ideas (Soyinka 1975). ... In an earlier effort to assist people in reading and studying 
Soyinka's poems and their political message, TundeAdeniran (1994) devised a four-point outline which he has listed as (a) poems based on Soyinka's personal experience (b) poems inspired by the experience of other individuals (c) poems informed by events in his immediate community (Nigeria) and (d) universal poems echoing the human condition. If he did this for a study of Idanre and Other Poems and A Shuttle in the Crypt, it is possible to do a study of this latest volume along the same route as the different sections of the volume have made possible.....

\section{Strength of Claim: Interaction between Move 1 and Move 2}

In the previous section, strength of claim was discussed in relation to Move 2. In this section, it is considered in relation to the interaction between Moves 1 and 2. First, let us consider an introduction that bases its claim on a robust Move 1, Step 3. RP3: (2005) Linguistics below is representative of a few of the cases where the authors explored all three Moves in order to map out their research territory and properly lay claim to a niche.

RP3: (2005) Linguistics:

MOVE 1: ESTABLISHING A TERRITORY, STEP 1: CLAIMING CENTRALITY:

[Serial verb constructions (SVCs, henceforth) have been explored extensively in many languages of the world.] MOVE 1, STEP 3: REVIEWING ITEMS OF PREVIOUS LITERATURE: [Serial verb constructions have been attested in languages of Southeast Asia, West Africa, New Guinea, Oceania, Australia, and some Central and South American languages (Bamgbose 1982, Durie 1997, Lord 1993, Alkhenvald 1999, Sebba 1987, Nylander 1997). In Ghana, a significant effort has been devoted to the study of the phenomenon in some languages. In particular, the Benue-Kwa group of languages such as Akan (Boadi 1968, Dolphyne 1987, Osam 1994) and Ewe (Ansre 1966, Agbedor 1993) has received a fair amount of attention in the treatment of serial verb constructions. Some studies have also been done on a few languages of the Gur group. Typical examples are Dagaare (Bodomo 2001, 2002, 1993; Saanchi 2002), Dagbani and Mampruli (Bodomo 1993) and Buli (Youngjoo 2003).]

MOVE 2: ESTABLISHING A NICHE, STEP 1B (INDICATING A GAP): In Gurene, however, there has not been a single study that is detailed enough to account for the characteristics of serialization in the language. Bodomo (1993) did an integrated study of serial verb constructions on what he calls the Mabia languages (which include Dagaare, Dagbani, Mampruli and Gurene) but unfortunately less than ten example sentences were cited in Gurene. Thus, his analysis was not comprehensive enough as far as Gurene is concerned. Also Dakubu (2003) made a proposal for a criterion for recognizing a structure as an SVC in the languages of the Volta Basin and included a discussion on 
Gurene SVCs. However, since her focus was not on Gurene SVCs not much was said about it.

MOVE 3: OCCUPYING THE NICHE: STEP 1A (OUTLINING PURPOSES): The present paper therefore, attempts an analysis of serial verb constructions in Gurene with the objective of characterizing the key features in the language. It is my hope that new insights would be gained and thus increase knowledge in the already existing body of literature in this phenomenon.

MOVE 3: STEP 3 (INDICATING RA STRUCTURE): The rest of the work is organized as follows: section 2 gives the sources of the data for the study, section 3 looks at the definition of SVCs from a typological perspective whilst section 4 examines SVCs typology in Gurene. Section 5 considers common predicates used in SVCs in the language with section 6 on grammaticalization and serial verb constructions. Section 7 is the conclusion.

In the introduction above, the author claims centrality for the specific research area, and through an extensive review of the literature (Move 1, Step 3) prepares the ground for claiming his research space. Move 2 in this introduction is distinctive for its elaborateness. The author lines up studies done in the area (Bamgbose 1982; Durie 1997; Lord, Alkhenvald 1999; Sebba 1987; Nylander 1997); (Boadi 1968; Dolphyne 1987; Osam 1994) and Ewe (Ansre 1966; Agbedor 1993) etc.), and for each he uses contrast and negation (namely, "however", "there has not been a single study"; "but unfortunately less than"; "his analysis was not comprehensive enough"; "However, since her focus was not on Gurene SVCs not much was said about it.") to indicate the gap in the research. It is a very strong statement of what has not been done in the area. The use of the quantifiers ("a single study"; "less than"; "not much") underlies the lack of adequate research on the subject matter. Drawing predominantly from African sources, the author's claims are emphatic and robust, which may derive from the author's confidence in his knowledge of the research territory being reviewed.

In the following introduction, RP31: (2007) Performing Arts, review of items of previous literature was limited in extent:

31: (2007) Performing Arts: MOVE 1: ESTABLISHING A TERRITORY, 'COVERT' STEP 3: [A lot has been written about the traditional music of Ghana, and there are also some studies on some of the composers of Ghana.] MOVE 2: ESTABLISHING A NICHE, STEP 1B (INDICATING A GAP): [However, scant regard has been paid to the compositions of Isaac Daniel Riverson whose ground breaking pedagogical work, The Atlantis Music Readers, was used in all schools across the length and breadth of Ghana, and whose compositions touch on almost every facet of Ghana's history, from the colonial era to the time of independence.] 
MOVE 1: ESTABLISHING A TERRITORY, STEP 3: REVIEWING ITEMS OF PREVIOUS LITERATURE: [Some writers have touched on the compositions of composers like Amu and Nketia. Agawu (1984), for example, has discussed the importance of language on music compositions in Ghana, with particular reference to the musical style of Amu and concluded that Amu regarded parallelism in between speech tones and melodic contour as an essential compositional premise, and that Amu "strove continually to provide a 'translation' of his text into music."] MOVE 2: ESTABLISHING A NICHE, STEP 1B (INDICATING A GAP): [A point worthy of note is that Riverson was a contemporary of Amu and had his own views with regard to the importance of language on musical compositions; however, no reference is made to him by Agawu.] MOVE 1: ESTABLISHING A TERRITORY, STEP 3: REVIEWING ITEMS OF PREVIOUS LITERATURE: [Nketia also makes mention of Riverson in connection with the differences between Nketia and Riverson as regards notation of Ghanaian folk songs in his publication Folk Songs of Ghana;] MOVE 2: ESTABLISHING A NICHE, STEP 1B (INDICATING A GAP): [however, again the contributions of Riverson to the development of traditional music in Ghana are not mentioned.]

The need for the present study becomes even more imperative when one considers that Riverson'sSongs of the Akan Peoples was the second most significant collection of African songs after the publication of Amu's TwentyFive African Songs (more will be said of these two works later in this paper). MOVE 1: ESTABLISHING A TERRITORY, STEP 3: REVIEWING ITEMS OF PREVIOUS LITERATURE: Turkson (1987) and Mensah (1991) have both recognised the work that Riverson did especially with notation of traditional African rhythms. Mensah, for instance, notes "Riverson's collection of folk songs, especially from the traditional Fante lyric repertoire and arranged a few ... [and] set these to four-part harmony lest he ruined the essence". Mensah further points out that Riverson "strictly follows the tendency to match tone patterns in tune and text" especially in the lead cantor's part. It is in the light of these that the nationalistic works of Isaac Daniel Riverson are worthy of study.

This introduction, which contains multiple Moves (that is, the Moves are repeated in a cycle), begins with a generalization about prior literature. This generalization suggests that the author, after a review of the literature, can conclude that "a lot has been written" about the subject matter. In this regard and for purposes of verification and validation, some of these studies could have been cited. This is not done, and incidentally, the author's negotiation and declaration of research space chiefly hinge on three sources, namely Agawu (1984), Turkson (1987), and Mensah (1991), the currency of which, presumably, cannot be said to significantly strengthen the gap statements which have been reiterated across the introduction. For example, "however, scant regard has been paid to 
the compositions of Isaac Daniel Riverson; however, no reference is made to him; however, again the contributions of Riverson to the development of traditional music are not mentioned", which is further combined with a declaration of relevance in the sentence - "The need for the present study becomes even more imperative when one considers that Riverson's Songs of the Akan Peoples was the second most significant collection of African songs after the publication of Amu's Twenty-five African Songs". In sum, although the author tries to establish a niche in a robust manner through the reiteration of gap statements, the limited literature review items could reduce the persuasive strength of his Move 2.

In another example, RP27: (2007) Linguistics below, the author initiates content with topic generalizations which have a generic reference to prior studies done in the area "most previous treatments associated with" [+TOPIC] precluding any attempt at some literature review.

RP27: (2007) Linguistics: Most previous treatments associated with inalienable possessions in the Swahili language have concentrated on two particular construction types; one in which the possessor and the inalienable possession are respectively the direct and the oblique objects.

[EXAMPLE 1]

And to a lesser extent one in which the possessor and the inalienable possession are respectively subject and object.

[EXAMPLE 2]

With these two constructions above, (1) and (2), the Possessor Promotion of Possessor Raising rule applies. The person affected (agent of the verb) is represented by an object prefix in the verb. However, a third construction type, which is usually overlooked, is the subject of this paper. ...

Section 2 of the paper describes variants of the auto-referential affective construction. Section 3 considers the semantic range of the construction and the contextual features of the predicate. And section 4 discusses the possible restrictions that govern the choice of variant. Section five is the conclusion.

Therefore, the gap statement in Move 2 "However, a third construction type, which is usually overlooked, is the subject of this paper." is not backed by an explicit review of prior studies. We have to accept the claim of the author that the construction type is indeed overlooked. How then do we evaluate the relative merits of the gap statement? The lack of a robust contextualization of what is clearly a huge claim being made reduces the persuasive force of the introduction. The subject matter of the paper in question is the Swahili language, and it has attracted scholarly studies among academics all over the world, especially in East African as well as North American universities. Therefore, material exists for intertextual contextualisation of the gap statement. 
A further example is RP 59: (2010) Language which begins with a Move 3 (Occupying the Niche - Announcing present research). Move 2 of this introduction is structured in the form of a justification: "The study was undertaken because it is apparent that some English words have assumed a distinct mode of pronunciation in Ghana." There is reference to literature (prior knowledge); after which, there is another Move 2 signalled through a contrastive statement plus question raising, and the questions posed are multiple and consecutive.

RP 59: (2010) Language: This paper attempts to find out how students at the University of Ghana treat final stops, especially in monosyllabic words. We thus:

wanted to look at the tendency in younger students of the University of Ghana to elide final /t/ /d/ /b/ / / / /g/;

attempted to determine the prevalence of glottal stops (GS) as final stop substitutes; and

wanted to find out whether the subsequent sound and / or preceding sound influences the selection of final stop or not.

The study was undertaken because it is apparent that some English words have assumed a distinct mode of pronunciation in Ghana. 'But', for example, is often heard as [ba] or [ba?]. That a final consonant sound can be elided in Ghana is not unusual, after all, as was noted by Strevens (1965:113):

[QUOTE]

However, this quotation leads us into a further question: do aspects of pronunciation in Ghanaian English always reflect transfer phenomenon? In many Ghanaian languages the syllable structure does not have a consonantal coda, so one might wonder whether we are dealing with a transference phenomenon when students elide final stops. But as many students substituted final stops with a glottal stop, we have had to ask, where does the glottal stop come from? Whereas final consonant elision is a common feature of Student pidgin, glottal stops are rare in this code. Can the use of the glottal stop or the elision of final stops be explained by the number of Ghanaian students going to the UK to work during the summer vacation and picking up Cockney traits in their speech? Can the use of the glottal stop or the elision of final stops be a temporary fad inspired by, for example, TV announcers who use glottal stops? How widespread is the elision of the final stop or its substitution by a glottal stop?

A glottal stop, according to Gimson (1972:9), is produced when "the glottis is held tightly closed with the lung air pent up below it"....

Apart from the initial question, there are four additional questions which constitute Move 2 and which seek to create a gap. The literature review covers two items, namely, Strevens (1965) and Gimson (1972). For a paper that was published in 2010, the literature is clearly outdated being about four decades old. In this introduction, though 
Move 2 is emphatic largely because of the multiplicity of questions raised it is not anchored in an extensive review of the literature which arguably could have provided a much more thorough contextualization of the author's work.

\section{Conclusion}

Disciplinary conventions in the humanities call for a proper contextualization of current research in terms of prior knowledge, but what we find in the data is a rhetorical preference for claiming centrality and making topic generalizations with scant literature review. In summary, the analysis demonstrates that; (a) Move 1 is mostly characterized by a rhetorical preference for claiming centrality and making topic generalizations with limited literature review or none at all; (b) Move 2 is absent in a number of cases implying a lack of explicitness or robustness in establishing a territory prior to or as part of announcing present research; (c) Move 2 where explicit, the gap statement made is not backed by sufficient contextualization in the form of an extensive synthesis of prior knowledge, and this, arguably, weakens the strength of claim.

It has to be emphasized that the approach adopted here is not prescriptivist; rather the argument is that from the perspective of knowledge construction in the humanities the expectation is that the formulation of niche rhetoric should be grounded on a more robust review of prior literature. A Move 2 anchored on topic generalizations or merely claiming centrality without the benefit of prior literature would not attract acceptance and recognition for the author of the paper. The limited literature review probably reflects a lack of rigour on the part of the contributors to the journal in constructing "intertextual warrants" for the research spaces they are claiming or perhaps an uncanny nonchalant attitude towards the knowledge creation and dissemination process. It must be acknowledged though that while a robust or extensive review is important, its adequacy or rhetorical worth is both author and reader (as a member of the sub-disciplinary community) dependent. In re-constructing prior literature in order to establish a research territory/niche, an author's view of what constitutes adequacy is a strong determining factor; nonetheless, this in turn is ultimately subject to the expectations of other members of the sub-disciplinary community as well as accepted practices within the sub-discipline. I hasten to add that it is not the intention of this study to suggest that the pattern observed in the data may be characteristic of RA introductions in African scholarly communication. Indeed, as mentioned in the introduction to this paper, the literature indicates that niche rhetorical strategies differ across disciplines and cross-culturally. Therefore essentially, the value of this study is twofold. First, an analysis of published scholarly writing from a genre analytical perspective enables us to see how scholars make use of rhetorical strategies as part of their internalized sense of the communicative protocols governing the construction of knowledge in their disciplines. Second, it signals how language teachers, especially those involved in the teaching of academic writing courses in universities, can 
Adika, G. S. K. / Legon Journal of the Humanities 25 (2014) 58-75

use the material and the insights gained to help younger scholars particularly in second language contexts to deploy the rhetorical strategies more resourcefully. 


\section{References}

Aina, L. O. (1997). Research and writing skills workshop for librarians in Southern Africa: A workshop proposal. Gaborone, Botswana: University of Botswana Press.

Al-Ali, M. \& Sahawneh, Y. B. (2011). Rhetorical and textual organization of English and Arabic $\mathrm{PhD}$ dissertation abstracts in linguistics. SKY Journal of Linguistics, 24, 7-39.

Anthony, L. (1999). Writing research article introductions in software engineering: How accurate is a standard model? IEEE Transactions on Professional Communication, 42, 3846.

Bunton, D. (2002). Generic moves in Ph.D. thesis introductions. In J. Flowerdew (Ed.), Academic discourse (pp. 57-75). London, UK: Longman.

Crookes, G. (1986). Towards a validated analysis of scientific text structure. Applied Linguistics, 7, 57-70.

Dudley-Evans, T. (2000). Genre analysis: A key to a theory of ESP? Ibérica: Revista de la Asociación Europea de Lenguas para Fines Específicos (AELFE),2, 3-11.

Hyland, K. (2004). Disciplinary discourses: Social interactions in academic writing. Ann Arbor, MI: The University of Michigan Press.

Kwan, B. S. K., Chan, H., \& Lam, C. (2012). Evaluating prior scholarship in literature reviews of research articles: A comparative study of practices in two research paradigms. English for Specific Purposes, 31, 188-201.

Legon Journal of the Humanities, (2005), 16.

Legon Journal of the Humanities, (2006), 17.

Legon Journal of the Humanities, (2007), 18.

Legon Journal of the Humanities, (2008), 19.

Legon Journal of the Humanities, (2009), 20.

Legon Journal of the Humanities, (2010), 21.

Myers, A. (1999). Journal of Negro history. In K. A. Appiah \& H. L. Gates (Eds.), Africana: The encyclopaedia of African and African-American experience (pp. 1069-1072). New York, NY: Perseus.

Nwogu, K. N. (1997). The medical research papers: Structure and functions. English for Specific Purposes, 16, 119-138.

Posteguillo, S. (1999). The schematic structure of Computer Science research articles. English for Specific Purposes, 18, 139-160.

Samaraj, B. (2002). Introductions in research articles: Variations across disciplines. English for Specific Purposes, 21, 1-17.

Shehzad, W. (2008). Move Two: Establishing a niche. Ibérica, 15, 25-50. 
Stilwell, C. (2000). Venturing into academic journal publishing: Some issues and guidelines for new authors. Africa Journal of Library Archives and Information Science, $10(2), 167-175$.

Swales, J. 1981. Aspects of article introductions. Aston ESP Research Report No. 1. Language Studies Unit. University of Aston in Birmingham.

Swales, J. M. (1984). Research into the structure of introductions to journal articles and its application to the teaching of academic writing. In R. Williams, J. Swales, \& J. Kirkman (Eds.), Common ground: Shared interests in ESP and Communication Studies (pp. 77-86). Oxford, UK: Pergamon.

Swales, J. M. (1990). Genre analysis: English in academic and research settings. Cambridge, UK: Cambridge University Press.

Swales, J. M., \& Feak, C. B. (2004). Academic writing for graduate students: Essential skills and strategies. Ann Arbor, MI: University of Michigan Press. 